\title{
The Role of Innovation in the Segmentation Process
}

\section{Abbott J Haron*}

Business Department, Higher Colleges of Technology, Abu Dhabi, United Arab Emirates

\begin{abstract}
Marketing is a vital element for business success in today's world. Competition is cutthroat, making it challenging for competitors to survive in the market for lengthy periods. The core belief of marketing has become "adapt or die", which initiates the need for creativity and innovation in the traditional methods to marketing. Right and effective marketing strategies often involve a combination of several marketing strategies, which work together in a synergistic way to establish the brand, generate interest, and desire the product with the goal to achieve a competitive advantage over competing organizations. To successfully attain this, it is vital to device new creative methods of reaching a larger pool of consumers through applying creativity to the market segmentation practice. The subsequent discussion studies traditional market segmentation and recommends creative strategies while segmenting the market.
\end{abstract}

Keywords: Innovation; Marketing; Segmentation; Positioning; Marketers; Global brands; Market segmentation; Creativity; Traditional market segmentation; Digital platforms; Social media

\section{Introduction}

\section{The role of the creativity in the segmentation process}

To this researcher, creativity is a prevailing act or idea that is transformed into a new one. The world is dynamic and creativity is one of the main methods to obtain competitive advantage between different regions i.e., between developed and underdeveloped nations of the world [1]. Even within organizational levels, the role of creativity is vital for competitive advantage and the success of an economy in changing from an industrial production economy into innovative one [2]. The resources of the organization such as the management of knowledge and Research \& Development can assess creativity of an organization [3]. Due to the dynamic nature of the new business environment because of technological advances demonstrated in communication and manufacturing competition has increased in the market place, as result of production of goods and services by people and corporations determined to win new customers through sophisticated techniques to increase their market, profitability and preserve customer loyalty [4].

Yankelovich and Meer defined the segmentation process as the act of separating a market into different groups of buyers with diverse needs, characteristics or behaviours, who require separate products or marketing approaches [3]. It can likewise be viewed as a process of dividing the market into clearly smaller groups of consumers with same needs, wants and characteristics, then choosing one or more parts to target with a clearly defined and custom tailored marketing mix.

By using creativity, a business will be able to know buyers' needs and wants in different segments in which it intends to sell its products and services. This can be completed by finding out the need that is sufficiently persistent in segments' buying decisions, which are major factors like attitude, beliefs, motivation, and perception [5]. Furthermore, creativity can be realized through the experiences acquired during the process of dealing with the customers [1]. Subsequently, organizations must to define the offerings that will match their segments and the relevance of each offering to their customers. This will allow the organization to know the product or service that will be dealt with in their organizational strategy and help achieve organizational goals and objectives [6].

Aaker and Shansby defined positioning as implanting a brand's unique benefits and distinctions in customers' minds [7]. It is the place product occupies in customers' mind relative to opposing products i.e., position strategy supports the managers to understand how their organizational contributions are viewed by the customers [8]. Therefore, an organization must focus in developing a selling method that appeals to a targeted segment so that the customer will have a positive view of their products. Since we are living in a dynamic environment where tastes, opinions, preferences and personalities of consumers change rapidly from time to time, it is crucial for management to always evaluate the efficiency and usefulness of the organization's present positioning strategies of its brands in relation to competing products in the market to gain a sustainable competitive advantage [9].

Branding is significant as a means of differentiating a company's offerings, and differentiating one particular product from its contenders [4]. Given all the other elements like pricing, distribution, and promotion, branding is the means whereby the consumer can recognize a particular product, and if satisfied with it, might ask about its name. To this researcher, a brand retains such characteristics as a name, design, logo, or a combination, which can differentiate a specific service or product from another, this helps add value to it [6]. Brands inform the buyer of the products' quality, packaging, design, features, and benefits [4]. A brand that is backed up by laws is known as a trade mark. Pepsi cola, Coca Cola, and KFC are all examples of global brands. global brand is a type of brand that circumvents its origin and also shows the same values across countries and cultures [7]. These brands are sold in numerous markets and known by different consumers all over the world. In the case of Coca-Cola and Pepsi-Cola, there are authorized bottlers around the world who pay for the right to use the name. Global positioning is the rational for the organizational presence in the market place. Global positioning encompasses the development of certain marketing mix elements to change the entire perception of a product or organization by unrealized customers and new markets.

*Corresponding author: Abbott J Haron, Instructor, Business Department, Higher Colleges of Technology, CAA institution, Abu Dhabi, United Arab Emirates, Tel: +971 2-681 4600; E-mail: abbottjharon@gmail.com

Received December 13, 2015; Accepted December 28, 2015; Published January 08,2016

Citation: Haron AJ (2016) The Role of Innovation in the Segmentation Process. J Account Mark 5: 150. doi:10.4172/2168-9601.1000150

Copyright: @ 2016 Haron AJ. This is an open-access article distributed under the terms of the Creative Commons Attribution License, which permits unrestricted use, distribution, and reproduction in any medium, provided the original author and source are credited. 
Moreover, through global positioning, the organization will be able to realize where it should channels its efforts as to have the greatest impact on the business environment [4].

Furthermore, the organization may use product differentiation strategy to distinguish their products from those of rivals, by using other positioning strategies such as product attributes, competitors, prices, product class [7]. The suitability of a positioning strategy can be determined by testing the propose goals for consistency, clarity, feasibility, advantage, credibility and competitiveness [1].

Consumer behavioral patterns differ considerably between countries. Because of cultural differences amongst countries, there is a need to design a product to suit the country intended to be sold [10]. For example, Nestle coffee, and a host of similar products are marketed internationally under different characteristics like different names, flavors, logos and packaging. For example, in continental Europe, coffee drinkers prefer it strong and dark, however, consumers in the United States prefer a weaker, milder cup of coffee [11]. Similarly, what appeals to European consumers may not appeal to the American or African consumers. Eating frogs is perfectly acceptable in some countries, while in some African and Arab countries, frog eating is forbidden by culture and religion [12]. Product design is essential to global marketers who are in the practice of moving from one country to another in their marketing activities [5]. In this researcher's point of view, product design is the process of creating and developing of ideas that will lead to original new product [4]. This can be accomplished through understanding customers' needs, wants and desires [13]. Some of its aims are to combine science and technology to improve product quality, service performance, and reduce costs, consequently leading to sustainable competitive advantage in the perceived minds of the target market with respect to the organization's offerings [8].

It is crucial for global marketers to determine the reason, function and purpose the product intends to satisfy [3]. For example:

Agronomics: Human interface i.e., the kind of product designed to fit the target market in terms of people size and shape.

Aesthetics: Is concerned with the type of packaging or features the product will possess to attract specific consumers. Moreover, marketers will have to know the type of advertising strategy or sales strategy to attract the desired consumers [4].

Economic value: i.e., If the product is worth the price for which it was acquired for both inside and outside the country.

Customer: Is the one who makes use of the product. Global marketers must decide who is their target market or customers whom the product is created for.

Quality: Product quality or standard needs to be determined by global marketers in terms of substandard or standardized products depending on the target markets choices [14]. For instance, Chinese made phones are two categories: the substandard ones, which were created for the underdeveloped countries or markets while the standardized ones are for the developed countries or markets.

Environment (Eco-manufacturing, sustainability, recycling etc.)): How will the product impact the environment - recycling parts, raw materials used in manufacturing, the manufacturing process? Under these standards, global marketers will look at the environment of its target market and decide on a product design that will fit into the environment.
Safety: The global marketers must decide on the suitable impact of the product on the health and safety of the consumers within the environment in which the product is intended to be sold.

Usability and Reliability: marketers must ensure that the product is able to be used for the purpose it was built for and last for the period it was designed for.

Global marketers are concerned with moving from one nation to another in their marketing activities. Consequently, for the global marketers to flourish in their product design, they have to employ the design criteria that will apply to all countries in the world they intend to attract in their marketing efforts.

There are numerous global brands in the world today. Here are some of the world best global brands: Coca- cola, IBM, Ford, Google, Microsoft, Amazon, Gillette, Santander, Kellogg, Apple, Mercedes - Benz, Pepsi, HP, Blackberry, Nike, McDonalds. There are various reasons for the success of the above global brands; some are protection, responsiveness, presence, differentiation, and relevance.

Protection: Is the ability of the organization to protect the integrity of their brands, the above named brands continuously made sure that their brands are protected from the competitor's activities of copying and mimicking.

Responsiveness: Is the brand's capacity to respond to challenges, threats and market changes as a result of the dynamic business environment. The triumphs of the above brands can be seen in their ability to respond to the changes in the socio-economic, socio-cultural trends within local and global markets, like responding in people's changing tastes, attitudes, opinions, and values. This is because the customers are always eager to acquire new products because of changes in tastes and fashions. Therefore, various brands such as apple, Blackberry, Nokia etc... have been making efforts to respond to the changing needs and wants of the customers by harnessing the latest technology and through regular research and development activities.

Presence: This component examines the degree to which a brand is ubiquitous and how positively consumers and opinion formers discuss it in both traditional and social media. The rise in the social media brings presents better opportunities for brands to show their presence. Due to the dynamic nature of our business environment, customers are provided feedback online, thus replying genuinely and quickly to their desires, wants, and needs.

Differentiation: Is the degree to which consumers perceive a brand to have a position that is distinctive from the competition. In other words, differentiations are seen in the smart phones like Google, Apple and BlackBerry that have been very successful in carving out markets for themselves in the global business environment.

Understanding: Not only must customers distinguish the brand, but there must also be an in-depth understanding of its unique qualities and features as well as those of the brand owner. Apple, Toyota, Microsoft, Coca-Cola etc., are brands that consumers always understand.

Relevance: This element estimates how well a brand fits with customer requirements, desires, and decision criteria across various geographical and demographical regions in the world. The world in which we are living in is dynamic and brands must keep-up in order to be relevant in this environment.

Clarity: The brand's value positioning and proposition must be 
clearly expressed and shared across the organization, along with a clear view of its target audiences. It is crucial that those within the organization know and understand all the elements, because everything that follows centers on them. Clarity in other way shows the degree to which the brand and its owners are able to define the consumers' value. This is because the consumers are always redefining their values every day. There is a need for the organization to observe and interact with the consumers to address their recognized needs. This can only be accomplished when the organization has a clear view of what brand to offer to their customers. The global brands accomplishments are based on their commitments to understanding customers' needs and addressing them.

\section{Conclusion}

Experience has shown that value-creation, anticipating areas of development, increasing customer base, broadening product line, maintaining core values such as safety, luxury, excellence, pride in its products and innovation are the best ways of achieving success in this global dynamic business environment. Corporations need to develop effective strategies in their design and persuading the consumers in the global target market segments that will be profitable and sustainable.

\section{References}

1. Akaka MA, Alden DL (2010) Global brand positioning and perceptions. International Journal of Advertising 29: 37-56.

2. Hofstede G, Bond MH (1988) The Confucius Connection: From Cultural Roots to Economic Growth. Organizational Dynamics 16: 5-21.
3. Yankelovich D, Meer D (2006) Rediscovering Market Segmentation. Harvard Business Review 84: 122-131.

4. Aaker DA, Joachimsthaler E (1999) The Lure of Global Branding. Harvard Business Review 77: 137-144.

5. De Mooij M (2010) Global Marketing: Tailoring Your Strategy to Fit the Culture. Deep Insight.

6. Cayla J, Arnould EJ (2008) A Cultural Approach to Branding in the Global Marketplace. Journal of International Marketing 16: 88-114.

7. Aaker DA, Shansby JG (1982) Positioning Your Product. Business Horizons 25: 56-62.

8. Holt DB (1995) How Consumers Consume: A Typology of Consumption Practices. Journal of Consumer Research 1-16.

9. Douglas SP, Craig SC (1986) Global Marketing Myopia. Journal of Marketing Management 2: 155-169.

10. Calantone RJ, Cavusgil ST, Schmidt JB, Shin G (2004) Internationalization and the Dynamics of Product Adaptation - An Empirical Investigation. Journal of Product Innovation Management 21: 185-198.

11. Ananymous (2015) Illy. Retrieved from Illy, official coffee partner.

12. Viswanathan NK, Dickson PR (2007) The fundamentals of standardizing global marketing strategy. International Marketing Review 24: 46-63.

13. Zukin S, Jennifer SM (2004) Consumers and Consumption. Annual Review of Sociology 30: 173-197.

14. Cavusgil TS (1996) Pricing for global markets. The Columbia Journal of World Business 31: 66-78. 